\title{
Effect of varied tapering on the immune cells of endurance athletes in some selected training centers of Ethiopia
}

\author{
Ambachew Amede ${ }^{1}$, 다 Somoutra Mondal ${ }^{1}$, (i) Mathivanan Dhamodharan ${ }^{1}$, \\ Mahmud Abdulkedir ${ }^{2}$, (1) Enyew Assefa ${ }^{3}$ \\ ${ }^{1}$ Department of Sport science, College of Natural and Computational Sciences, Mekelle University, Mekelle, Ethiopia. \\ ${ }^{2}$ Institute of Medical Microbiology \& Immunology College of Medical Science, Mekelle University, Mekelle, Ethiopia. \\ ${ }^{3}$ Department of Statistics, College of Natural Science, Wollo University, Dessie, Ethiopia.
}

\begin{abstract}
The purpose of the present study was to recognize the effects of varied tapering strategies on the immune response of endurance athletes in some selected training centers of Ethiopia. Thirty-seven young distance runners (mean age: $20 \pm 1.97$ years; mean training age: 2.43 \pm .603 years) were randomly assign into the high intensitylow volume (HILV) and high intensity-moderate volume (HIMV) taper groups. Training frequencies were five times per week and conducted for two weeks in both groups. Before and after the two weeks taper intervention, the average lymphocyte concentration of the participant was measured and analyzed using CBC (sysmix) machine. There was no statistically significant difference in both within and between groups analyzed using the paired $t-$ test and ANCOVA. In conclusion, the finding revealed that both the HILV and HIMV tapering strategies don't have an influence on the immune response. Possible flue or cold that challenge the athletes during the precompetitions period might not relate to the taper training load, instead the psychological stress that occurs as a result of approaching the competition time may have a negative immune responses which demands consideration in the future research focuses.
\end{abstract}

Keywords. High intensity-low volume, high intensitymoderate volume, immunology, lymphocytes, tapering.

\section{Introduction}

Regularly practiced hard training and the wider knowledge of progressive overload training regimens severely disrupt the balance between training and recovery methods of the athletes (Neary et al., 2003). Contemporary coaches, athletes and training expertise have difficulties to find strategies to increase performance. An increase in the level of fatigue, mood disturbance and decrease in performance occurred when there was imbalance between training and recovery (Halson, 2003). Most of the reports related to overtraining were mainly caused by insufficient recovery periods after the long exhaustive training (Zatsiorsky, 2003). All strategies did before a major competition was intended to boost performances by reducing the training loads and cumulated fatigue effects (Kentta et al., 2001; Matos, 2010). Due to the above fact, exercise scientists were looking for different alternative training interventions, recovery methods, and dietary intake to increase the performance of an athlete (Mujika, 2009).

Tapering is among these strategies that most athletes and their coaches were used to refreshing their fatigued muscle and mind (Bosquet et al., 2007;

Received: March 04, 2019 - Accepted: June 01, 2019 - Published: September 10, 2019

To cite this article: Amede A, Mondal S, Dhamodharan M, Abdulkedir M, Assefa E. Effect of varied tapering on the immune cells of endurance athletes in some selected training centers of Ethiopia. Turk J Kinesiol, 2019; 5(3): 102-109. 
Bompa \& Haff, 2009). Tapering is defined as a short period of reduction in the athletes' training load during few days/weeks prior to a major competition (Brannstrom et al., 2013). It was characterized by a high intensive and low volume training programs (Mujika et al., 2000). The high intensive training program performed for a short period of duration could help to provide sufficient stimuli to initiate adaptation (Bosquet, 2013; Neary et al., 2003).

Though; intensive exercises were associated with a high probability of developing upper respiratory tract infection (Bishop, 2006). The J-shaped model revealed that athletes involved in an intensive exercise or a prolonged period of heavy exercise training might have high prevalence than the sedentary groups (Nieman et al., 2003). Studies suggest that performing moderately intensive exercise regularly helps to improved immune function and a reduced incidence of infection (Bishop, 2006). Though; excessive training load could cause immune system depression and increased susceptibility to infection (Gleeson, 2007). The immune system is large and complex and has a wide variety of functions. The main role of the immune system is to defend the individual against germs and microorganisms (Nieman et al., 2007) and age, gender eating habits, medical status, training, and fitness level are among the several factors that might influence the daily functioning of the immune system (Nielsen, 2013).

Performing high intensity exercise is associated with a depression of immune function (Gleeson, 2007; Hemila et al., 2003) which increase the incidence of infection experienced by athletes. Chronic depression of immune function could occur during a period of strenuous exercise that performs without sufficient time for recovery (Meeusen et al., 2013).

There was an elevated level of stress hormones during a period of strenuous exercise and acute bouts of exercise could cause a temporary depression of various aspects of immune function (example, neutrophil, lymphocyte) lasting for 3-24 hours after exercise, depending on the intensity and duration of the exercise bout (Gleeson, 2012). According to Gleeson (2012), periods of intensified training (overreaching) lasting for seven days or more result in chronically depressed immune function indicate that sore throats and flu-like symptoms are more common in endurance athletes than in the general population.

A substantial increase in the number of circulating leukocytes (mainly lymphocytes and neutrophils) were observed after intensive training and the magnitude of which is related to both the intensity and duration of exercise (Northoff, 1998) and this is remarkably similar in many respects to those induced by infection (Bishop, 2006). These changes returned to pre-exercise values within 3-24 hours after training (Gleeson, 2007). Cross-sectional studies by Gleeson, (2007) have compared leukocyte numbers and functions in blood samples taken from athletes more than 24 hours after their last training session with those of sedentary individuals have very few differences. Shephard et al. (1999) also made similar study between the athletes and nonathletes and true resting state, immune function appears to be similar in athletes compared with nonathletes.

Research on the effects of exercise on the immune function encompasses a wide range of sporting activities including short-term, exhaustive activity, endurance, and long term activities, and regular light exercise. In recent years, studies have shown the role of physical stress on the immune system and examined the effects of exercise on immune function (Meeusen et al., 2013). There was an increase in the lymphocyte count and percentages in response to an acute exercise but further increase the intensity and durations did not increase it (Blannin et al., 1996). Increases in the lymphocytes responses to high intensive and long duration exercise are starting to fall back even below that of the baseline levels (Giraldo et al., 2009).

Exercise related stress is the leading causes of respiratory tract infections in athletes. For instance colds, coughs and other throat infections are common in athletes (Graham, 2001). These illnesses 
present a real concern to the well-being of both athletes and the general population and therefore an understanding of the relationship between physical activity and infection risk is of great importance. A very familiar and mostly used model that shows relationship between exercise intensity/volume and susceptibility to upper respiratory tract infection was the J-shaped model (Nieman, 2003). The J-shaped model explains that taking part in regular moderate physical activity decreases the relative risk of upper respiratory tract infections below that of a sedentary individual but performing high intensity or prolonged exercise is associated with an above-average risk of upper respiratory tract infections. Further interest has been raised by the researcher to compare the effects of varied training loads on the immune response particularly with regard to the relationship between high intensity low volume and high intensity moderate volume in endurance athletes. This provides us additional evidence to consider when assessing the relationship between training load and infection level.

Several reports have noted that high-intensive training increased the frequency of respiratory system infectious disease in athletes (Hoffman-Goetz \& Pedersen, 1994; Sharpley \& Christie, 2009). Since the exercise intensity remain high during the precompetition (taper) periods, there was also a high probability of developing infection even during this critical pre competition time. The intension of this study is to investigate and compare the effects of the varied tapering strategies on the immune responses in endurance athletes in selected athletics training centers (ATC) of Ethiopia.

\section{Methods}

The centers of attention were the two athletics training centers (Maychew and Tenta) found in Tigray and Amhara regional states of Ethiopia at an altitude of 2860 and $2679 \mathrm{~m}$ meters above sea level and 625 and $520 \mathrm{~km}$ far from Addis Ababa, the capital city of Ethiopia respectively.
No one is being affected by this research study. Ethical approval was assured from the Ethical committee of Mekelle University with reference no: ERC0772/2016. Participant Consent was guaranteed. Information confidentiality and individual's right were boldly stated

\section{Sample and Sampling Techniques}

Thirty seven competitive endurance athletes from Maychew and Tenta ATC were volunteered to participate in this study. Total population (Census sampling) could be used because they are few in numbers and all are taken as a sample. Athletes who are going to be competitive, have minimum training experience of two years, engage in training regularly for the last 3 months, free from illness or injury conditions, weekly training load comprises $25 \mathrm{~km}$ $50 \mathrm{~km}$ could be included and those who are not competitive, are not in training regularly for the last three months, have less than two year training experience, have known health problems, recently injury conditions were not included.

\section{Design of the Study}

Pre- post research design with parallel group setting was used. Participant athletes were assigned to the high intensity-low volume (HLt) and high intensitymoderate volume (HMt) taper intervention groups using block randomization techniques.

\section{Data Analysis}

Initially, the data were tested for assumptions of normality using the Shapiro-Wilks and Kolmogorov Smirnov Test and it confirms normal distribution. Demographic characteristics of the participant athletes were assessed and analyzed using descriptive statistics. Independent t-test (comparing the baseline differences between groups), paired-test (pre \&post test scores differences) and ANCOVA (posttest difference between groups) were used. Results were reported by using $\mathrm{M} \pm \mathrm{SD}$ and $\mathrm{MD}$. The level of significance was set at $\alpha=0.05, \mathrm{p}<0.05)$. SPSS 20.0 version was used for all above analysis. 


\section{Results}

According to the table 1 above, there was no significant difference $(\mathrm{P}>.05)$ between the high intensity-low volume and high intensity moderate volume taper groups in both variables. Therefore, any possible changes occurred after the taper might be considered as a result of the taper intervention program.

According to the paired t-tests analysis (table 2), There was no statistically significant changes in the lymphocyte counts and its percentages within the HILV \& HIMV taper groups. This means the HILV and HIMV taper strategies had not influenced the immune response in the participant athletes. When there was an infection due to the taper, there might be a significant change in the immune response. So, one can be certain that, the was no possible experience in developing an infection as a result of HILV and HIMV taper applied before an important competition.

A one way between group analyses of covariance was conducted to compare the effectiveness of the two different interventions designed to investigate the Lymphocyte percentages and absolute count. The independent variable was the two taper interventions (high intensity-low volume and high intensity-moderate volume) and the dependent variable consists of the scores of the lymphocyte percentages and absolute counts. Participant's score on the pre-intervention administration of the lymphocyte concentration was used as the covariate in this analysis. Preliminary checks were conducted to ensure that there was no violation of the assumption of normality, homogeneity of variance and reliability measurement of covariate.

Table 1

Baseline Lymphocyte percentages and absolute counts between groups.

\begin{tabular}{lccccccc}
\hline Variables & Groups & $\mathrm{n}$ & $\mathrm{M}$ & $\mathrm{SD}$ & $\mathrm{t}$ & $\mathrm{df}$ & $\mathrm{p}$ \\
\hline Lymphocyte percentages & HILV & 20 & 33.65 & 7.42 & -.355 & 37 & .903 \\
& HIMV & 19 & 34.53 & 7.98 & & & \\
Absolute Lymphocyte count & HILV & 20 & 1.75 & .44 & .787 & 37 & .724 \\
& HIMV & 19 & 1.63 & .49 & & & \\
\hline
\end{tabular}

$H I L V=$ high intensity - low volume taper groups, HIMV = high intensity moderate volume taper group.

Table 2

Paired sample t-test of the Lymphocyte percentages and absolute count Within the HILV and HIMV taper groups.

\begin{tabular}{|c|c|c|c|c|c|c|c|}
\hline \multirow{2}{*}{ Groups } & \multirow{2}{*}{ Variables } & Pre & Post & \multirow{2}{*}{ MD } & \multirow{2}{*}{$\mathrm{t}$} & \multirow{2}{*}{ df } & \multirow{2}{*}{$\mathrm{p}$} \\
\hline & & $\mathrm{M} \pm \mathrm{SD}$ & $\mathrm{M} \pm \mathrm{SD}$ & & & & \\
\hline \multirow{2}{*}{ HILV } & Absolute Lymphocyte count & $1.75 \pm .44$ & $1.60 \pm .503$ & -.15 & -1.14 & 19 & .267 \\
\hline & Lymphocyte percentages & $33.65 \pm 7.42$ & $37.60 \pm 7.21$ & 3.95 & 1.96 & 19 & .065 \\
\hline \multirow{2}{*}{ HIMV } & Absolute Lymphocyte count & $1.59 \pm .51$ & $1.76 \pm .44$ & .177 & 1.14 & 16 & .269 \\
\hline & Lymphocyte percentages & $34.71 \pm 8.01$ & $35.29 \pm 7.04$ & .588 & .251 & 16 & .805 \\
\hline
\end{tabular}

$H I L V=$ high intensity- low volume taper groups, HIMV = high intensity moderate volume taper group. 
Table 3

Posttest comparison of lymphocyte percentages and absolute counts between groups (ANCOVA).

\begin{tabular}{llllllll}
\hline Variables & Groups & $\mathrm{N}$ & $\mathrm{M} \pm \mathrm{SD}$ & $\mathrm{df}$ & $\mathrm{F}$ & $\mathrm{p}$ & $\mathrm{Partial} \mathrm{n}^{2}$ \\
\hline Absolute Lymphocyte count & HILV & 20 & $1.60 \pm .50$ & 1.34 & 1.363 & .251 & .040 \\
& HIMV & 19 & $1.76 \pm .44$ & & & & \\
Lymphocyte percentage & HILV & 20 & $37.60 \pm 7.21$ & 1.34 & 1.082 & .306 & .032 \\
& HIMV & 19 & $35.29 \pm 7.04$ & & & & \\
\hline
\end{tabular}

$H I L V=$ high intensity- low volume taper groups, HIMV = High intensity- moderate volume taper groups.

As seen in the table 3 above, there was no significant difference $(p>0.05)$ between the two groups in the absolute lymphocyte counts and percentages at $\mathrm{F}(1,34)=1.363, \mathrm{p}=.251$, partial eta squared $=0.04(4 \%)$ and $F(1,34)=1.082, p=.306$, partial eta squared $=.032(3.2 \%)$.

\section{Discussions}

This research was aimed to investigate and compare the effects of taper training on the possible upper respiratory infections marker of white blood cells particularly on the lymphocytes cells percentages and absolute counts. The assumptions set at the initial was stated as the high intensity-low volume (HILV) and the high intensity moderate volume (HIMV) taper strategies might have significant effects on the possible upper respiratory infection marker of white blood cells in endurance athletes. The set objectives and assumption were intended to see what would happen on the infection markers of white blood cells (lymphocyte percentages and the absolute lymphocyte counts ) due to the two weeks high intensity-low volume and high intensitymoderate volume taper training. Both the lymphocyte percentages and absolute lymphocyte cell counts were used to detect the changes in response to the tapering strategies used.

The findings from the paired t-test and subsequent ANCOVA showed that there was no statistically significant change $(p>.05)$ both within and between the HILV \& HIMV taper groups (table 2 and 3). This means that there was no or less possibility of getting upper respiratory infection occurred due to the two weeks HILV and HIMV taper intervention training in endurance athletes. This may be due to the reasons that the pre taper exhaustive training practiced during the specific preparation periods could push the body to work beyond the physiological limits and help to initiate early kickoff immunization by which the body develops natural resistance for future exposure to similar exercise related stresses (Gibala, 2007). Thus, the body considered as nothing was newly introduced during the taper phase, except for the mode of delivery which basically done in the forms of short intervals with adequate recovery period between sets.

These rational analogues were supported by Aggarwal et al., (2008) in which acute exercises are useful to enhance the immune cells and muscle adaptations, by which the production and release of new neutrophils and monocyte from the bone marrow were stimulated. Physiological adaptation would be initiated when intensive training followed by adequate recovery periods (Petersen and Pedersen, 2005). As the bodies once develop an immune adaptation, chronic metabolic and cardio respiratory risks would minimize regardless of the fluctuations in training related stress (Gleenson et al., 2011). These adaptive effects are responsible for the developments of acquired immune efficiency in athletes (Kraus, 2002).

In line with this, Kubukeli et al. (2002) and Ross \& Leveritt (2001) provide evidence that high intensity interval training per section is a potent stimulus to 
induce physiological adaptations that resemble adaptations in typically traditional endurance training, despite a lower total exercise volume and reduced training time in exercise. Similar research finding conducted by Giraldo et al. (2009) showed that an increase in the lymphocytes responses during the high intensive and long duration exercise employed during the high load training phase is well documented and used as a reference level when training load particularly the volume was reduced during the pre-competition period. Indeed, trained endurance athletes incorporate high intensive interval training as an integral component of their training programs designed to maximize performance (Laursen \& Jenkins, 2002). A brief review highlighted by Burgomaster et al. (2005) and Gibala et al. (2015) sheds light on the effectiveness of low volume and high intensive interval training to induce rapid physiological adaptation and making in shape to improve the energy system and performance capacity as like the actual competition.

However; contradict findings was reported from Papacosta \& Gleeson (2013), stating as engagements in highly-intensive exercise could have detrimental effects on immune function and the different feature of immune function, for instance, the respiratory burst, lymphocyte propagation, the antigen production depends on the intensity and duration of the exercise bout (Walsh et al., 2011). The higher the intensity the lower the adaptation of the immune cell to such training related stress (Fahlman \& Engels, 2005). Here what needs to be emphasis is not simply the high intensive exercise that causes respiratory tract infection, quite many other things such as psychological stress, disturbed sleep, and negative energy balance may contribute to immune suppression in competitive athletes (Nieman et al., 2007). Acute bouts of high intensive interval training applied to succeed to exhaustive general preparation could have beneficial effect to induce positive physiological adaptations (Laursen \& Jenkins; 2002; Walsh et al., 2011). However; long hours of hard training made the athlete more susceptible to upper respiratory tract infections (Bishop, 2005; Nieman et al., 2003).

As a result, manipulating the training components (the intensity and volume) during the tapering period has no influence on the immune cells response especially on lymphocytes counts and percentages that could help to predict the athlete's infection status. There was no statistically significant change in either from the paired t-test or ANCOVA results both within and between groups respectively. In general, negative immune cell response was not commonly observed during the tapering periods due to the training load alterations.

\section{Funding}

No external funding was received for this study.

\section{Declaration of Interest}

The authors report no conflict of interest.

\section{References}

Aggarwal AF, Liao M, Mosca L. Physical activity and perceived exertion during a two hours run. Journal of Sport Psychology, 2008; 27(3): 286-292.

Bishop D, Edge J. The effects of a 10-day taper on repeated-sprint performance in females. Journal of Science and Medicine in Sport; 2005; 8(2); 200-209.

Bishop NC. Immune Function in Sport and Exercise. In: Advances in Sport and Exercise Science Series. Exercise and infection risk. Chapter one. Churcuil Living Stone, Elsevier, 2006.

Blannin AK, Chatwin IJ, Cave R, Gleenson M. Effects of sub maximal cycling and long-term endurance training on neutrophil phagocytic activity in middle aged men. $\mathrm{Br} \mathrm{J}$ Sports Med, 1996; 30(2): 125-129.

Bompa TO, Haff GG. Periodization theory and methodology. IL, Human Kinetics, 2009.

Bosquet L, Berryman N, Dupuy O, Mekary S, Arvisais D, Bherer L, Mujika I. Effect of training cessation on muscular performance: A meta-analysis, research review. NJ, USA, Blackwell Publishing Ltd., 2013.

Bosquet L, Montpetit J, Arvisais D, Mujika I. Effects of Tapering on Performance: A Meta-Analysis. Medicine and Science in Sports and Exercise, 2007 39(8): 1358-1365. 
Brannstrom A, Rova A, Yu J. Effects and mechanisms of tapering in maximizing muscular power. Sport and Art, 2013; 1(1): 1823.

Burgomaster KA, Hughes SC, Heigenhauser GF, Bradwell SN, Gibala MJ. Six session sprint interval training increases muscle oxidation potential and cycle endurance capacity in humans. Journal of Applied Physiology, 2005; 98(6): 19851990.

Fahlman MM, Engels HJ. Mucosal IgA and URTI in American college football players: a year longitudinal study. Medicine and Science in Sports and Exercise, 2005; 37(3): 374-380.

Gibala, Martin J. (2007). High-intensity interval training: A timeefficient strategy for health promotion? Sports Medicine Reports, Current Medicine Group LLC 6: 211-213.

Giraldo E, Garcia JJ, Hinchado MM, Ortega E. Exercise intensitydependent changes in the inflammatory response in sedentary women: role of neuroendocrine parameters in the neutrophil phagocytic process and the pro-/antiinflammatory cytokine balance. Neuroimmunomodulation, 2009; 16(4): 237-44. 355.

Gleeson M. Detection and prevention of overtraining in athletes. Overtraining lecture summary. School of Sport, Exercise and Health Sciences, Loughborough University, 2012.

Gleeson E. Immune function in sport and exercise. J Appl Physiol, 2007; 103: 693-699.

Gleeson M, Bishop N, Stensel DJ, Lindley MR, Mastana SS, Nimmo MA. The anti-inflammatory effects of exercise: mechanisms and implications for the prevention and treatment of disease. Nat Rev Immunol, 2011; 11: 607-615.

Graham TE. Caffeine and exercise: Metabolism, endurance and performance. Sports med 2001; 31: 785-807.

Halson SL, Lancaster GI, Jeukendrup AE, Gleeson M. Immunological responses to over-reaching in cyclists. Med Sci Sports Exerc, 2003; 35: 854-861.

Hemila H, Virtamo J, Albanes D. Physical activity and the common cold in men administered vitamin $\mathrm{E}$ and $\beta$-carotene. Medicine and Science in Sports and Exercise, 2003; 35: 18151820.

Hoffman-Goetz L, Pedersen BK. Exercise and the immune system: A model of the stress response? Immunol Today, 1994; 15(8): 382-387.

Kentta G, Hassman P, Raglin JS. Training practices and overtraining syndrome in Swedish age group athletes. International Journal of Sport Medicine. 2001; 22: 1-6.

Krause M. Exercise, Sarcopenia and Immuno senescence. Accessed from http://back-in-businessphysiotherapy.com/images/files/exercise_sracopenia_and_i mmunsenescence.pdf, Australia, 2002.
Kubukeli ZN, Noakes TD, Dennis SC. Training techniques to improve endurance performance. Sport Med, 2002; 32: 489509.

Laursen PB, Jenkins DC. The scientific basis for high-intensity interval training optimising training programmes and maximising performance in highly trained endurance athletes. Sport Med, 2002; 32(1): 53-73.

Meeusen R, Duclos M, Foster C, Fry A, Gleeson M, Nieman D, Raglin J, Rietjens G, Steinacker J, Urhausen A. Prevention, diagnosis, and treatment of the overtraining syndrome: Joint consensus statement of the European college of sport science and the American College of Sports Medicine. Medicine and Science in Sports and Exercise, 2013; 15(1): 186-205.

Mujika I, Goya I, Padilla S, Grijalba A, Gorostiaga E, Ibanez J. Physiological responses to a six days taper in middle distance runners: influence of training intensity and volume. Med Sci Sports Exerc, 2000; 32: 511-517.

Mujika I. Tapering and peaking for optimal performance. IL, USA, Human Kinetics, 2009.

Neary JP, Martin TP. Quinney HA. Effects of taper on endurance cycling capacity and single muscle fiber properties. Medicine \& Science in Sports \& Exercise. 2003; 35: 1875-1881.

Nielsen HG. Exercise and Immunity. Accessed from https://www.intechopen.com/books/current-issues-insports-and-exercise-medicine/exercise-and-immunity.

Nieman DC, Henson DA, Gross SJ, Jenkins DP, Davis JM, Murphy EA, Carmichael MD, Dumke CL, Utter AC, McAnulty SR, McAnulty LS, Mayer EP. Quercetin reduces illness but not immune perturbations after intensive exercise. Medicine and Science in Sports and Exercise, 2007; 39(9): 1561-1569.

Nieman DC, Davis JM, Brown VA, Henson DA, Dumke CL, Utter AC, McAnulty LS. Influence of carbohydrate ingestion on immune changes after $2 \mathrm{~h}$ of intensive resistance training. J Appl Physiol, 2003; 96: 1292-1298.

Northoff H, Berg A, Weinstock C. Similarities and differences of the immune response to exercise and trauma: The IFNgamma concept. Can J Physiol Pharmacol, 1998; 76(5): $497-$ 504.

Papacosta E, Gleeson M. Effects of intensified training and taper on immune function. Rev Bras Educ Fís Esporte, 2013; 27(1): 159-176.

Petersen AM, Pedersen BK. The anti-inflammatory effect of exercise. J Appl Physiol, 2005; 98(4): 1154-1162.

Ross A, Leverritte M. Longterm metabolic and skeletal muscle adaptation to short sprint training. Implication for sprint training and tapering. Sport Med, 2001; 31: 1063-1082. 
Sharpley CF, Christie DR. Effects of interval between diagnosis and survey up on preferred information format for prostate cancer patients. J Med Imaging Radiate, 2009; 53(2): 221-225.

Shephard RJ, Shek PN. Effects of exercise and training on natural killer cell counts and cytolytic activity: a meta-analysis. Sports Med, 1999; 28: 177-195.

Walsh NP, Gleeson M, Shephard RJ, Woods JA, Bishop NC, Fleshner M, Green C, Pedersen BK, Hoffman-Goetz L, Rogers CJ, Northoff H, Abbasi A, Simon P. Position statement. Part one: Immune function and exercise. Exerc Immunol Rev, 2011; 17: 6-63.

Zatsiorsky VM. Biomechanics in Sport. Performance enhancement and injury Prevention. Encyclopedia of sport medicine IOC Medical commission. Vol: IX, Jonkopping University, Blackwell Science, 2003. 